\title{
Synthesis and characterization of novel thienyl-phthalazine based heterocyclic systems functionalized with (bi)thiophene moieties
}

\author{
$\underline{\text { Sara S. M. Fernandes, M. Manuela M. Raposo* }}$ \\ Centro de Química, Universidade do Minho, Campus de Gualtar, 4710-057, Braga, Portugal \\ Email: mfox@quimica.uminho.pt
}

\begin{abstract}
The phthalazine moiety has a highly $\pi$-deficient aromatic character that makes it a good candidate to be incorporated as electron acceptor group, or even as spacer with auxiliary electron withdrawing abilities, into push-pull systems. Additionally, offers the possibility of protonation, hydrogen bond formation, and chelation through the nitrogen atoms.
\end{abstract}

Phthalazine derivatives have applications as therapeutic agents, chemiluminescent materials, ligands in transition metal catalysis, and as optical materials.

Some time ago, our research group developed a methodology for the preparation of phthalazine derivatives in three steps, affording halo-thienyl-phthalazine derivatives that play an important role in diazine chemistry since they offer great potential for further functionalization by nucleophilic displacement of the halogen, making numerous otherwise inaccessible diazines become available.

In continuation of the work developed before by our research group, we report in this communication the synthesis and the evaluation of the optical properties of two novel thienylphthalazine derivatives, having in mind further functionalization to prepare push-pull heterocyclic systems for several optical and photovoltaic applications. These studies showed that the optical properties could be readily tuned by varying the $\pi$-conjugation path length through the introduction of a second thiophene unit. 


\section{Introduction}

For the last decades, research targeting dipolar chromophores has been considerably growing due to its interesting and tuneable properties and numerous applications as therapeutic agents, ${ }^{1}$ chemiluminescent materials, ${ }^{2}$ ligands in transition metal catalysis, ${ }^{3}$ and as optical materials. ${ }^{4}$

The electronic arrangement of push-pull compounds is based on an electron donor group (D) and an electron acceptor group (A) interacting through a $\pi$-conjugated spacer, allowing for intramolecular charge-transfer (ICT). The tuning of the molecular properties of these systems for the desired applications can be achieved through modification of the electron donor or acceptor end-cap groups, or modification of the $\pi$-bridge. Recently, the incorporation of heterocycles with different electronic natures (electron-rich or electron deficient) into the $\pi$ conjugated systems has proven to induce higher photochemical and thermal stabilities and will modulate the optoelectronic properties. ${ }^{5}$ The phthalazine moiety is a good candidate to be incorporated into dipolar systems as electron acceptor group, or as a spacer with auxiliary electron withdrawing abilities due to its highly $\pi$-deficient aromatic character. It also allows for further functionalization though protonation, hydrogen bond formation, and chelation through the nitrogen atoms. ${ }^{6}$

Some time ago, this research group reported the preparation of halo-thienyl-phthalazine derivatives, that can play an important role in diazine chemistry due to their great potential for further functionalization by nucleophilic displacement of the halogen. ${ }^{7}$ In continuation of the work developed by this research group in the preparation of push-pull heterocyclic systems for several optical and photovoltaic applications, ${ }^{3 b-c, 7-8}$ we report the synthesis and the evaluation of the optical properties of two novel thienyl-phthalazine derivatives as precursors in the preparation of a large variety of donor-acceptor $\pi$-conjugated chromophores.

\section{Experimental}

\subsection{Methods and Materials}

NMR spectra were obtained on a Varian Unity Plus Spectrometer at an operating frequency of $300 \mathrm{MHz}$ for ${ }^{1} \mathrm{H}$ NMR using the solvent peak as internal reference at $25^{\circ} \mathrm{C}$ ( $\delta$ relative to TMS). 
All chemical shifts are given in Hz. Assignments were made by comparison of chemical shift, peak multiplicities and $J$ values. UV-Visible absorption spectra $(200-800 \mathrm{~nm})$ were obtained using a Shimadzu UV/2501PC spectrophotometer. Fluorescence spectra were collected using a FluoroMax-4 spectrofluorometer. Luminescence quantum yields were measured in comparison with ethanol solution of 9,10-diphenylanthracene $\left(\Phi_{F}=0.95\right)^{9}$ as standard. All melting points were measured on a Gallenkamp melting point apparatus and are uncorrected.

All reagents were purchased from Aldrich or Acros Organics and used as received. TLC analysis were carried out on $0.25 \mathrm{~mm}$ thick precoated silica plates (Merck Fertigplatten Kieselgel $60 \mathrm{~F}_{254}$ ) and the spots were visualized under UV light. Chromatography on silica gel was carried out on Merck Kieselgel (200-300 mesh). The synthesis of precursor 3-bromo-6(thiophen-2-yl)phthalazine 1 was reported elsewhere. ${ }^{7}$

\subsection{Synthesis}

General procedure for the synthesis of 3-(thiophen-2-yl)phthalazine derivatives 3a-b from 3bromo-6-(thiophen-2-yl)phthalazine 1 by Suzuki-Miyaura cross-coupling:

3-Bromo-6-(thiophen-2-yl)phthalazine $\mathbf{1}^{7}(0.5 \mathrm{mmol})$ was coupled with the appropriate heterocyclic boronic acid $2(0.6 \mathrm{mmol})$ in a mixture of DME $(8 \mathrm{~mL})$, ethanol $(2 \mathrm{~mL})$, aqueous $2 \mathrm{M} \mathrm{Na}_{2} \mathrm{CO}_{3}(1 \mathrm{ml})$ and $\mathrm{Pd}\left(\mathrm{PPh}_{3}\right)_{4}(5 \mathrm{~mol} \%)$ at $80{ }^{\circ} \mathrm{C}$, under nitrogen. The reaction was monitored by TLC, which determined the reaction time (48 h). After cooling, the mixture was extracted with chloroform $(3 \times 20 \mathrm{ml})$ and a saturated solution of $\mathrm{NaCl}(20 \mathrm{~mL})$. The organic phase was washed with water $(3 \times 10 \mathrm{~mL})$ and with $10 \mathrm{~mL}$ of a solution of $\mathrm{NaOH}(10 \%)$. The organic phase obtained was dried over $\mathrm{MgSO}_{4}$, filtered, and the solvent removed to give a crude mixture. The crude product was purified through a silica gel chromatography column using mixtures of dichloromethane and light petroleum of increasing polarity to afford the coupled products 3. Recrystallization from $n$-hexane / dichloromethane gave the pure compounds.

1-(5'-Hexylthiophen-2'-yl)-4-(thiophen-2''-yl)phthalazine 3a. Yellow solid (26\%). UV (ethanol): $\lambda_{\max } \mathrm{nm}\left(\varepsilon, \mathrm{M}^{-1} \mathrm{~cm}^{-1}\right) 360(17,538) .{ }^{1} \mathrm{H} \mathrm{NMR}\left(\mathrm{CDCl}_{3}, 300 \mathrm{MHz}\right) \delta 0.90\left(\mathrm{t}, 3 \mathrm{H}, \mathrm{CH}_{3}\right.$, $J=7.0 \mathrm{~Hz}$ ), $1.33\left(\mathrm{~m}, 4 \mathrm{H}, \underline{\mathrm{C}}_{2} \mathrm{C}_{2} \mathrm{CH}_{2} \mathrm{CH}_{3}\right), 1.40$ (m, 2H, $\underline{\mathrm{C}}_{2} \mathrm{CH}_{3}$ ), 1.76 (quint, 2H, thioph$\left.\mathrm{CH}_{2} \mathrm{C}_{2}\right), 2.90$ (t, 2H, thioph- $\left.\underline{\mathrm{H}}_{2}, J=7.6 \mathrm{~Hz}\right), 6.91$ (d, 1H, H-4', $\left.J=3.6 \mathrm{~Hz}\right), 7.22$ (dd, 1H, 
H-4', $J=4.8 \mathrm{~Hz}, J=3.6 \mathrm{~Hz}), 7.55$ (d, 1H, H-3', $J=3.6 \mathrm{~Hz}$ ), 7.57 (dd, 1H, H-5', $J=5.2 \mathrm{~Hz}$, $J=1.2 \mathrm{~Hz}$ ), 7.68 (dd, 1H, H-3" $, J=3.6 \mathrm{~Hz}, J=1.2 \mathrm{~Hz}$ ), 7.87 (m, 2H, H-6, H-7), 8.47-8.50 (m, 1H, H-8), 8.52-8.56 (m, 1H, H-5) ppm. HRMS: m/z (EI) for $\mathrm{C}_{22} \mathrm{H}_{22} \mathrm{~N}_{2} \mathrm{~S}_{2}$; calcd 378.1224; found: 378.1222 .

1-(5' '-Hexyl-(2',2' '-bithiophen)-5'-yl)-4-(thiophene-2','-yl)phthalazine 3b. Yellow solid (19\%). UV (ethanol): $\lambda_{\max } \mathrm{nm}\left(\varepsilon, \mathrm{M}^{-1} \mathrm{~cm}^{-1}\right) 398,(20,045) .{ }^{1} \mathrm{H} \mathrm{NMR}\left(\mathrm{CDCl}_{3}, 300 \mathrm{MHz}\right) \delta 0.90$ (t, $3 \mathrm{H}, \mathrm{CH}_{3}, J=6.8 \mathrm{~Hz}$ ), 1.26-1.43 (m, 6H, $\left.\underline{\mathrm{C}}_{2} \mathrm{C}_{2} \underline{\mathrm{C}}_{2} \mathrm{CH}_{3}\right), 1.69$ (m, 2H, thioph- $\mathrm{CH}_{2} \mathrm{C}_{2}$ ), 2.79 (t, 2H, thioph- $\left.\underline{\mathrm{H}}_{2}, J=7.4 \mathrm{~Hz}\right), 6.71$ (d, 1H, H-4' ', $\left.J=3.6 \mathrm{~Hz}\right), 7.10$ (d, 1H, H-3' ', $J=3.6$ Hz), 7.17 (d, 1H, H-4', J = 3.6 Hz), 7.22 (dd, 1H, H-4', , $J=5.2 \mathrm{~Hz}, J=3.6 \mathrm{~Hz}), 7.57$ (dd, 1H, H-5 ', , $J=5.2 \mathrm{~Hz}, J=1.2 \mathrm{~Hz}$ ), 7.60 (d, 1H, H-3', $J=3.6 \mathrm{~Hz}$ ), 7.68 (dd, 1H, H-3 ' , , $J=3.6 \mathrm{~Hz}$, $J=0.8 \mathrm{~Hz}$ ), 7.87-7.92 (m, 2H, H-6, H-7), 8.46-8.52 (m, 2H, H-5, H-8) ppm. HRMS: m/z (EI) for $\mathrm{C}_{26} \mathrm{H}_{24} \mathrm{~N}_{2} \mathrm{~S}_{3}$; calcd 460.1102; found: 460.1103 .

\section{Results and Discussion}

\subsection{Synthesis}

Two heterocyclic chromophores were designed and synthesized, having in mind further functionalization to prepare push-pull heterocyclic systems for several optical and photovoltaic applications. Both $\pi$-conjugated systems are based on an electron deficient phthalazine moiety as spacer, substituted with hexyl-(bi)thienyl groups.

The preparation of precursor 3-bromo-6-(thiophen-2-yl)phthalazine $\mathbf{1}$ has been previously reported by this research group elsewhere. ${ }^{7}$ The final chromophores 3a-b where obtained by Suzuki-Miyaura cross-coupling between precursor $\mathbf{1}$ and selected boronic acids $\mathbf{2}$ in fair yieds $(19-26 \%)$.

Heterocyclic chromophores 3 were characterized by standard spectroscopic techniques. The presence of two (3a) or four (3b) new aromatic protons in the ${ }^{1} \mathrm{H}$ NMR analysis is observed, due to the protons of the thiophene(s) $\operatorname{ring}(\mathrm{s})$ as well as a set of signals that are attributed to the aliphatic protons of the hexyl chain. 


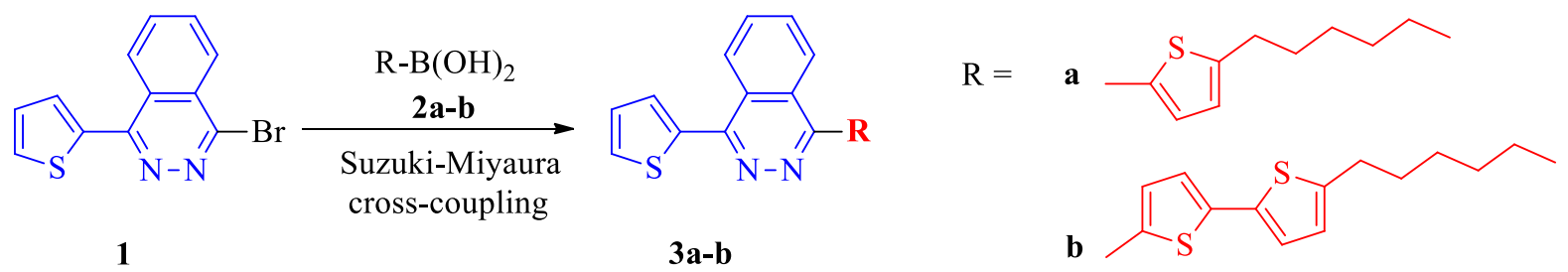

Scheme 1. Synthesis of 3-(thiophen-2-yl)phthalazine derivatives 3: $\mathrm{DME}, \mathrm{Pd}\left(\mathrm{PPh}_{3}\right)_{4}$, 5-hexyl2-thiopheneboronic acid 2a or 5'-hexyl-2,2'-bithiophene-5-boronic acid $\mathbf{2 b}, \mathrm{EtOH}, \mathrm{Na}_{2} \mathrm{CO}_{3}$

$$
\text { (aq), } \mathrm{N}_{2} \text {. }
$$

\subsection{Optical Study}

The optical absorption spectra of 3-(thiophen-2-yl)phthalazine derivatives $\mathbf{3}$ in ethanol solutions $\left(10^{-4} \mathrm{M}\right)$ show intense absorption bands at 360 and $398 \mathrm{~nm}$ for chromophores 3a and $3 \mathbf{b}$, respectively. The results showed that the introduction of a second thiophene unit into the system induced a bathochromic shift of $38 \mathrm{~nm}$ that can be attributed to the increase of extension of the $\pi$-conjugated path length (Table 1, Figure 1).

Phthalazines 3 were excited at the wavelength of maxima absorption, at room temperature, in order to study their fluorescence properties (Table 1, Figure 1). The relative fluorescence quantum yields were determined using a solution of 9,10-diphenylanthracene in ethanol as fluorescence standard $\left(\Phi_{F}=0.95\right) .{ }^{9}$ Chromophore 3a exhibits weak emissive properties $\left(\Phi_{F}=\right.$ $0.02)$, while chromophore $\mathbf{3 b}$ shows a higher relative quantum fluorescence yield (0.22). The bathochromic shift of $91 \mathrm{~nm}$ in the fluorescence spectra and the increase of the relative quantum fluorescence yield of chromophore $\mathbf{3 b}$ compared to $\mathbf{3 a}$ can be explain having in mind the functionalization of the heterocyclic system by an additional thiophene ring. ${ }^{10}$

Table 1. UV-visible absorption and emission data for thienyl-phthalazines $\mathbf{3}$, in ethanol.

\begin{tabular}{llllll}
\hline \multirow{2}{*}{ Cpds } & \multicolumn{4}{l}{ UV-vis } & \multicolumn{4}{l}{ Fluorescence } \\
\cline { 2 - 6 } & $\lambda_{\max }(\mathrm{nm})$ & $\varepsilon\left(\mathrm{M}^{-1} \mathrm{~cm}^{-1}\right)$ & $\lambda_{\mathrm{em}}(\mathrm{nm})$ & $\Phi_{F}$ & Stokes' shift $(\mathrm{nm})$ \\
\hline 3a & 360 & 17,538 & 429 & 0.02 & 69 \\
3b & 398 & 20,045 & 520 & 0.22 & 122 \\
\hline
\end{tabular}




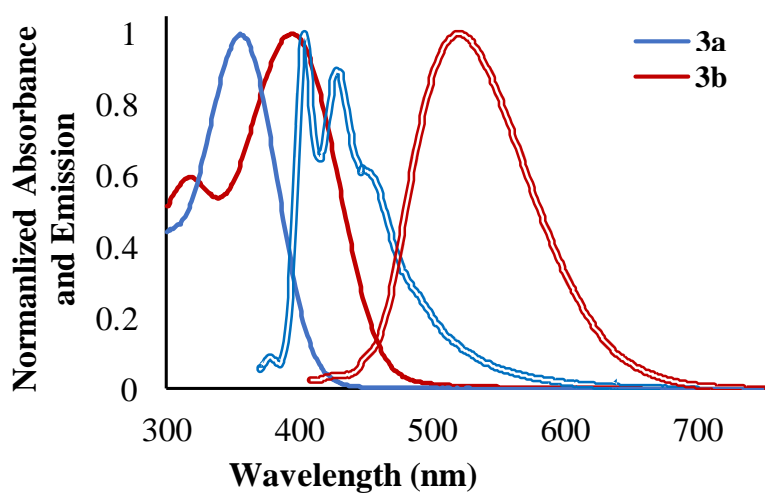

Figure 1. Normalized UV-visible absorption (full line) and emission (double line) data for thienyl-phthalazines 3a-b, in ethanol.

\section{Conclusions}

Two novel thienyl-phthalazine derivatives functionalized with hexyl-(bi)thienyl moieties have been synthesized by Suzuki-Miyaura cross-coupling in fair yields.

The study of the optical properties of the prepared chromophores showed the effect caused by the introduction of a second thiophene into the conjugated system in the UV-vis absorption and emission properties: bathochromic shifts in the absorption and emission spectra, as well as increased relative quantum fluorescence yield.

Due to their optical properties, $\pi$-conjugated heterocyclic systems 3 are versatile precursors that could be used for the preparation of nonlinear optical (SHG, TPA), OLEDs and DSSCs materials.

\section{Acknowledgements}

Thank are due to Fundação para a Ciência e Tecnologia (Portugal) and FEDER-COMPETE for financial support through Centro de Química (UID/QUI/00686/2013 and UID/ QUI/0686/2016), and a PhD grant to S. S. M. Fernandes (SFRH/BD/87786/2012). The NMR spectrometer Bruker Avance III 400 is part of the National NMR Network and was purchased within the framework of the National Program for Scientific Re-equipment, contract REDE/1517/RMN/2005 with funds from POCI 2010 (FEDER) and FCT. 


\section{References}

1. Vila, N.; Besada, P.; Costas, T.; Costas-Lago, M. C.; Terán, C., Phthalazin-1(2H)-one as a remarkable scaffold in drug discovery. Eur. J. Med. Chem. 2015, 97, 462-482.

2. (a) Achelle, S.; Baudequin, C.; Plé, N., Luminescent materials incorporating pyrazine or quinoxaline moieties. Dyes Pigments 2013, 98 (3), 575-600; (b) Yoshida, H.; Ureshino, K.; Ishida, J.; Nohta, H.; Yamaguchi, M., Chemiluminescent properties of some luminol related compounds (II). Dyes Pigments 1999, 41 (3), 177-182; (c) Achelle, S.; Rodríguez-López, J.; Katan, C.; Robin-le Guen, F., Luminescence behavior of protonated methoxy-substituted diazine derivatives: toward white light emission. J. Phys. Chem. C 2016, 120 (47), 2698626995.

3. (a) Kolb, H. C.; VanNieuwenhze, M. S.; Sharpless, K. B., Catalytic asymmetric dihydroxylation. Chem. Rev. 1994, 94 (8), 2483-2547; (b) Figueiredo, H.; Silva, B.; Raposo, M. M. M.; Fonseca, A. M.; Neves, I. C.; Quintelas, C.; Tavares, T., Immobilization of Fe(III) complexes of pyridazine derivatives prepared from biosorbents supported on zeolites. Microporous Mesoporous Mater. 2008, 109 (1-3), 163-171; (c) Figueiredo, H.; Silva, B.; Quintelas, C.; Raposo, M. M. M.; Parpot, P.; Fonseca, A. M.; Lewandowska, A. E.; Bañares, M. A.; Neves, I. C.; Tavares, T., Immobilization of chromium complexes in zeolite Y obtained from biosorbents: Synthesis, characterization and catalytic behaviour. Appl. Catal., B: Environ. 2010, $94(1-2), 1-7$.

4. (a) Cheng, Y.; Ma, B.; Wudl, F., Synthesis and optical properties of a series of pyrrolopyridazine derivatives: deep blue organic luminophors for electroluminescent devices. J. Mater. Chem. 1999, 9 (9), 2183-2188; (b) Achelle, S.; Rodríguez-López, J.; Bureš, F.; Robinle Guen, F., Dipicolylamine styryldiazine derivatives: Synthesis and photophysical studies. Dyes Pigments 2015, 121, 305-311; (c) Cvejn, D.; Achelle, S.; Pytela, O.; Malval, J.-P.; Spangenberg, A.; Cabon, N.; Bureš, F.; Robin-le Guen, F., Tripodal molecules with triphenylamine core, diazine peripheral groups and extended $\pi$-conjugated linkers. Dyes Pigments 2016, 124, 101-109.

5. (a) Zhu, X.-H.; Peng, J.; Cao, Y.; Roncali, J., Solution-processable single-material molecular emitters for organic light-emitting devices. Chem. Soc. Rev. 2011, 40 (7), 3509-3524; (b) Bureš, F., Fundamental aspects of property tuning in push-pull molecules. RSC Adv. 2014, 4 (102), 
58826-58851; (c) Klikar, M.; Solanke, P.; Tydlitát, J.; Bureš, F., Alphabet-inspired design of (hetero)aromatic push-pull chromophores. Chem. Rec. 2016, 16 (4), 1886-1905.

6. Achelle, S.; Plé, N.; Turck, A., Incorporation of pyridazine rings in the structure of functionalized $\pi$-conjugated materials. RSC $A d v$. 2011, 1 (3), 364-388.

7. Raposo, M. M. M.; Sampaio, A. M. B. A.; Kirsch, G., A convenient access to thienylsubstituted phthalazines. J. Heterocycl. Chem. 2005, 42 (7), 1245-1251.

8. (a) Castro, M. C. R.; Belsley, M.; Raposo, M. M. M., Push-pull second harmonic generation chromophores bearing pyrrole and thiazole heterocycles functionalized with several acceptor moieties: Syntheses and characterization. Dyes Pigments 2016, 128, 89-95; (b) Castro, M. C. R.; Belsley, M.; Raposo, M. M. M., Synthesis and characterization of push-pull bithienylpyrrole NLOphores with enhanced hyperpolarizabilities. Dyes Pigments 2016, 131, 333-339; (c) Fernandes, S. S. M.; Castro, M. C. R.; Mesquita, I.; Andrade, L.; Mendes, A.; Raposo, M. M. M., Synthesis and characterization of novel thieno[3,2- $b]$ thiophene based metalfree organic dyes with different heteroaromatic donor moieties as sensitizers for dye-sensitized solar cells. Dyes Pigments 2017, 136, 46-53; (d) Fernandes, S. S. M.; Mesquita, I.; Andrade, L.; Mendes, A.; Justino, L. L. G.; Burrows, H. D.; Raposo, M. M. M., Synthesis and characterization of push-pull bithiophene and thieno[3,2-b]thiophene derivatives bearing an ethyne linker as sensitizers for dye-sensitized solar cells. Org. Electron. 2017, 49, 194-205.

9. Morris, J. V.; Mahaney, M. A.; Huber, J. R., Fluorescence quantum yield determinations. 9,10-diphenylanthracene as a reference standard in different solvents. J. Phys. Chem. 1976, 80, 969-974.

10. Bernard Valeur; Berberan-Santos, M. N., Molecular fluorescence: principles and applications. 2nd ed.; Wiley-VCH: Weinheim, Germany, 2012. 